\title{
Performances of PA hollow fiber membrane with the CTA flat sheet membrane for forward osmosis process
}

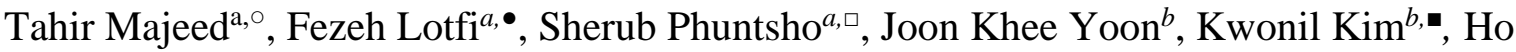 \\ Kyong Shon ${ }^{\mathrm{a}, *}$ \\ a School of Civil and Environmental Engineering, Faculty of Engineering and Information Technology, University \\ of Technology, Sydney (UTS), PO Box 123, Broadway, 2007 Australia \\ ${ }^{\circ}$ Phone:+61-2-95142673, Email: tahir.majeed@ student.uts.edu.au \\ •Phone:+61-2-95142659, Email: fezeh.lotfi@student.uts.edu.au \\ ${ }^{\square}$ Phone:+61-2-95142528, Email: sherub.phuntsho@uts.edu.au \\ b Samsung Cheil Industries Inc. 332-2, Gocheon-Dong, Uiwang-Si, Gyeonggi-Do, 437-711, Republic of Korea, \\ Phone: +82-31-5963408, Email: jjoon76.yoon@samsung.com \\ - Phone: +82-31-5963408, Email: kwonil1.kim@samsung.com \\ *Phone:+61-2-95142629, *Email: $\underline{\text { Hokyong.shon-1@uts.edu.au }}$
}

\begin{abstract}
Fertilizer drawn forward osmosis (FDFO) desalination has been earlier explored using flat sheet forward osmosis (FSFO) membrane which highlighted flux and reverse solute flux (RSF) performance. This study evaluated and compared the performances of a newly developed polyamide (PA) based hollow fiber FO (HFFO) membrane and cellulose triacetate (CTA) FSFO membrane. Both membranes were evaluated for pure water permeability (PWP), salt rejection rate $(1000 \mathrm{mg} / \mathrm{L} \mathrm{NaCl})$ in $\mathrm{RO}$ mode. Physical structure and morphology were further examined using scanning electron micrograph (SEM). SEM images revealed that the overall thickness of the HFFO and FSFO membranes was $152 \mu \mathrm{m}$ and $91 \mu \mathrm{m}$ respectively. Flux and RSF performances of these two membranes were evaluated using nine fertilizer DS as $\mathrm{NH}_{4} \mathrm{Cl}$, $\mathrm{KNO}_{3}, \mathrm{KCl},\left(\mathrm{NH}_{4}\right)_{2} \mathrm{SO}_{4}, \mathrm{Ca}\left(\mathrm{NO}_{3}\right)_{2}, \mathrm{NH}_{4} \mathrm{H}_{2} \mathrm{PO}_{4},\left(\mathrm{NH}_{4}\right)_{2} \mathrm{HPO}_{4}, \mathrm{NaNO}_{3}$ and $\mathrm{CO}\left(\mathrm{NH}_{2}\right)_{2}$ in active layer -feed solution membrane orientation. HFFO membrane clearly showed better performance for water flux with five DS $\left(\left(\mathrm{NH}_{4}\right)_{2} \mathrm{SO}_{4}, \mathrm{NH}_{4} \mathrm{H}_{2} \mathrm{PO}_{4}, \mathrm{KNO}_{3}, \mathrm{CO}\left(\mathrm{NH}_{2}\right)_{2}\right.$ and $\mathrm{NaNO}_{3}$ ) as they showed up to $66 \%$ increase in flux. Beside thick PA active layer of HFFO membrane, higher water flux outcome for FO process further highlighted the significance of the nature of support layer structure, the thickness and surface chemistry of the active layer of the membrane in the FO process. On the other hand, most DS showed lower RSF with HFFO membrane with the exception of $\mathrm{Ca}\left(\mathrm{NO}_{3}\right)_{2}$. Most of DS having monovalent cation and anions showed significantly lower RSF with HFFO membrane.
\end{abstract}

Keywords: Fertilizer draw solution, Forward osmosis (FO), Flat sheet FO membrane, Flux, Hollow fiber FO membrane, Reverse salt flux 


\section{Introduction}

Energy intensive thermal and membrane based desalination processes are currently being used extensively to meet the growing demands of clean water. The rising energy prices have really made it difficult to economically produce good quality water. Although thermal desalination was initiated many decades ago, but due to comparatively low energy systems, in the last 30 years, membrane based desalination processes gained popularity and now competing the long established distillation based technologies [1]. Membrane based technologies now claim major share of the installed desalination capacity in the world [2].

Forward osmosis (FO) is a newly introduced membrane based desalination technique harnessing the natural available power i.e., osmotic pressure (OP) of draw solution (DS) to induce flux thus avoids any additional external energy source to drive desalination. Due to this particular reason, in a very short period of time, FO technology has been evaluated for a wide range of applications ranging from sea / brackish water desalination [3-5] to power generation [6]. Fertilizer drawn forward osmosis (FDFO) is an innovative FO process [7] using commercially available fertilizers as DS to desalinate water for agricultural use. Additionally, opposite to other FO processes, final diluted draw solution does not necessarily require separation of the remaining DS and thus product permeated water is used directly for fertigation. It helps FDFO process taking a real advantage from low cost forward osmosis desalination approach.

Beside aforesaid FO inherent advantages, FO membrane and DS characteristics are considered as the major impediments in the commercialization of forward osmosis system [8]. Similarly, FDFO process has also seen certain limitations for its practical applications [7]. Apart from the fertilizer DS related issues such as excessive DS recovery, high nutrients concentration in permeated water, risk of possible nutrients loss to feed solution, membrane associated issues such as low water flux and high RSF are also noticed. FO flux is directly linked to initial capital cost and operating cost of FO system. High flux FO operation means small FO plant footprint and reduced reverse solute flux (RSF) reflects reduction of DS leakage to FO waste streams.

FO membranes are mainly classified into two main groups 1) flat sheet and 2) hollow fiber. Earlier studies with CTA flat sheet FO (FSFO) membranes highlighted issues such as low water flux $\left(\mathrm{J}_{\mathrm{w}}\right)$ and high $\operatorname{RSF}[9,10]$ which also affect FDFO process directly. Lower 
performance ratio of $16.48 \%$ indicated serious issues with FSFO membrane [7]. Initially, only the asymmetric (active layer embedded on a porous support layer-used to increase the structural strength of the membrane) FSFO membrane was produced and tested for various applications. The asymmetric structure of this membrane causes enhancing concentration polarization (CP) on both sides of the membrane consequently results in reduction of the actual water flux through the membrane. CP drastically reduces the available driving force (osmotic pressure gradient $(\Delta \pi))$ at the membrane surface and causes sharp decline in flux that results in poor FO operational result performance.

Since FO flux mainly relies on $\Delta \pi$ across the membrane surface contacting DS and feed solution (FS) to drive osmosis, therefore, the accumulated CP affects it seriously [11-14]. External concentration polarization (ECP) is usually linked with DS and FS concentration whereas internal concentration polarization (ICP) is mainly associated with thick dense membrane and support layer structure [9]. Membrane fouling and concentration polarization are considered as the two serious operational problems with FO systems directly affecting their outcome [12-16]. To overcome this issue, efforts were directed to develop an ideal FO membrane having thin film on a highly porous and very fine support layer, having high water permeability, low salt permeability and enough strength structure layers that gives minimum CP effects, especially ICP.

HTI first introduced commercial flat sheet CTA FO membrane [15]. To reduce the intensity of the membrane related issues critical for quick FO commercialization, many research groups worked on development of new and improved FO membranes. Some of the resulted positive outcomes include novel dual layer hollow fiber membranes [17], well-constructed cellulose acetate FO membrane [12], thin film composite FO hollow fiber membrane [18, 19], high performance thin film membrane [20], thin film nano composite using functionalized multiwalled nanotubes [21], double skinned FO membrane [22], acetylated methyl cellulose (AMC) membrane [23], cellulose triacetate/cellulose acetate (CTA/CA)-based membranes [24] etc.

Hollow fiber forward osmosis (HFFO) membrane development work was initiated by various research groups $[25,26]$ to produce better performing FO membrane carrying minimum FO operational issues. In comparison to FSFO membranes, most of the developed HFFO membranes demonstrated proven performance in terms of high water flux and lower RSF [19, 27-32]. 
Up to date many studies have been done to explore FO use in different practical applications using FSFO membrane but no serious attempt is yet made for using HFFO [33-39]. Hence this study may be considered as a late first genuine step to evaluate HFFO membrane for any commercial application as FDFO.

As such, the main objective of this study was to categorically compare HFFO membrane performance with FSFO membrane and notice its effects on FDFO desalination process efficiency. HFFO membrane was evaluated for different fertilizer DS and flux, RSF results were compared with the FSFO membrane outcome to identify specific membrane properties critical for higher FO process performances. Comparison of FDFO performance for these two different membranes with multiple DS further provided us better understanding about how different DS properties and membrane characteristics manipulate FO output.

\section{Materials and methods.}

\subsection{Experimental Set-up}

Bench scale HFFO set-up as shown in the Fig. 1 was used for this study. Two peristaltic pumps (Cole- Palmer, U.S.A.) were used to supply FS and DS to HFFO membrane module. Cross sectional flow rates were maintained at $400 \mathrm{ml} / \mathrm{min}$ for both FSFO and HFFO membrane units. While changing DS, each FO system was washed thoroughly at the end of each test for 30 minutes using distilled water at $400-800 \mathrm{ml} / \mathrm{min}$. Temperature of the DS and FS stream was kept constant at $25^{\circ} \mathrm{C} \pm 1^{\circ} \mathrm{C}$ using temperature water bath controlled by heater/chiller.

Water permeation through HFFO membrane was evaluated by measuring weight loss of FS using a weighing scale (CUW $4200 \mathrm{H}$ by CAS, Korea) connected to a computer data logging system which was later used to calculate water flux in these particular FO tests. A conductivity data logger probe was immersed in FS tank to record changes in FS conductivity at certain time intervals. This data helped in measuring RSF during FO operations. An identical bench scale FO set-up was used for FSFO membrane evaluation stated elsewhere [7]. 


\subsection{Membranes used}

HFFO membrane lumens, supplied by Samsung Cheil Industries, Korea were used in this study. HFFO lumens were composed of active polyamide (PA) thin film composite (TFC) layer

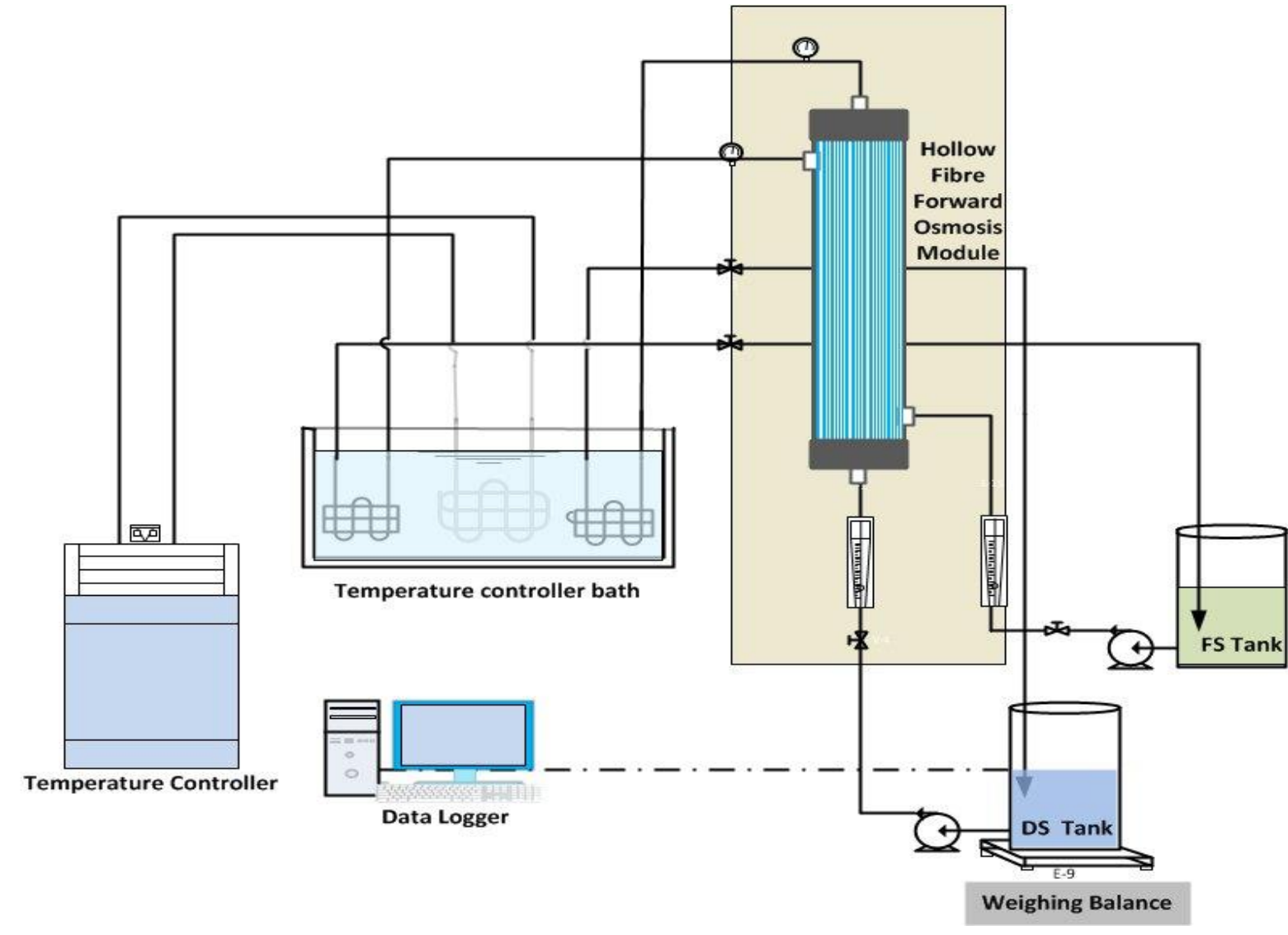

Fig. 1. Schematics of lab scale HFFO set-up used in this study

inside of porous polyethersulphone hollow fiber substrate. Inside and outside diameter of these hollow fiber lumens were $0.9 \mathrm{~mm}$ and $1.2 \mathrm{~mm}$ respectively and HFFO module carried average FO membrane area of $3.96 \times 10^{-2} \mathrm{~m}^{2}$.

Simultaneously, commercially available CTA forward osmosis membrane supplied by Hydration Technologies Innovations (HTI), USA was used separately with FSFO lab-setup. FO lab experimental cell carried flat-sheet membrane of size $26 \mathrm{~mm} \times 77 \mathrm{~mm}$. Thus FSFO membrane represented an average membrane area of $2.02 \times 10^{-3} \mathrm{~m}^{2}$.

All tests for both FSFO and HFFO were carried out in active layer - feed solution (AL-FS) membrane orientation. Smooth active layer of FSFO membrane was placed towards FS side and rough surface carrying polyester mesh support layer was faced towards DS side. Similarly, 
for HFFO set-up, FS was directed to flow through lumens whereas DS was flowed through FO module shell outside fiber.

\subsection{Chemicals and reagents}

9 commonly used fertilizers including $\mathrm{NH}_{4} \mathrm{Cl},\left(\mathrm{NH}_{4}\right)_{2} \mathrm{SO}_{4}, \mathrm{KNO}_{3}, \mathrm{KCl},\left(\mathrm{NH}_{4}\right)_{2} \mathrm{HPO}_{4}$ (DAP), $\mathrm{NH}_{4} \mathrm{H}_{2} \mathrm{PO}_{4}$ (MAP), $\mathrm{Ca}\left(\mathrm{NO}_{3}\right)_{2}, \mathrm{NaNO}_{3}$, and $\mathrm{CO}\left(\mathrm{NH}_{2}\right)_{2}$ (Urea) were selected to use as DS to evaluate and compare performance of these two FO membranes for FDFO process. Membrane performance was evaluated against $1 \mathrm{M}$ individual fertilizer DS concentration. DI water was used as FS for the whole study.

\subsection{FO operating setup summary}

Details of the HFFO and FSFO membrane test set-up are summarized in Table 1.

Table 1. Summary of the operating conditions for bench scale HFFO and FSFO membrane systems for FDFO process comparative study

\begin{tabular}{|l|l|}
\hline Description & Details \\
\hline DS used & $\begin{array}{l}\mathrm{NH}_{4} \mathrm{Cl},\left(\mathrm{NH}_{4}\right)_{2} \mathrm{SO}_{4}, \mathrm{KNO}_{3}, \mathrm{KCl},\left(\mathrm{NH}_{4}\right)_{2} \mathrm{HPO}_{4}, \\
\mathrm{NH}_{4} \mathrm{H}_{2} \mathrm{PO}_{4}, \mathrm{Ca}\left(\mathrm{NO}_{3}\right)_{2}, \mathrm{NaNO}_{3}, \text { and } \mathrm{CO}\left(\mathrm{NH}_{2}\right)_{2}\end{array}$ \\
\hline Fertilizer DS concentrations & $1 \mathrm{M}$ \\
\hline Feed water type & Deionized (DI) water \\
\hline Membrane orientation & $\mathrm{AL}-\mathrm{FS}$ \\
\hline Temperature & $25^{\circ} \mathrm{C} \pm 1.0$ \\
\hline Parameters evaluated & FO flux and RSF \\
\hline HFFO module type & $\begin{array}{l}\text { PA lumens based hollow fiber module } \\
\text { CTA flat sheet membrane }\end{array}$ \\
\hline $\begin{array}{l}\text { DS/FS flow rates } \\
\text { FSFO membrane active area }\end{array}$ & \begin{tabular}{l}
$2.02 \times 10^{-3} \mathrm{~m}^{2}$ \\
\hline HFFO membrane active area
\end{tabular} \\
\hline
\end{tabular}

\section{Results \& discussion}




\subsection{HFFO and FSFO membranes comparison}

HFFO and FSFO membranes were used for FDFO process comparison. Physical properties of both membranes are summarized in Table 2. Membrane thickness was evaluated using micrometer and its surface characteristics were further assessed using scanning electron micrograph (SEM). HFFO membrane comparatively shows about 66\% overall higher membrane thicknesses as HFFO and FSFO membranes show thickness of $152 \pm 3 \mu \mathrm{m}$ and $91 \pm 2$ $\mu \mathrm{m}$ respectively. Thus the HFFO thickness is about $66 \%$ higher than FSFO membrane. Similarly thickness of polyamide active layer of HFFO membrane is also high as compared to thickness of active CTA layer of FSFO membrane.

Pure water permeability (PWP) and the salt rejection rate $(1000 \mathrm{mg} / \mathrm{L} \mathrm{NaCl})$ of both membranes were evaluated in RO mode. FSFO membrane was evaluated for higher pressure (5-15 bars) whereas HFFO was evaluated at extremely low pressure (up to 1.5 bars) to avoid fiber damage. The PWP and the salt rejection of the HFFO membrane were $1.80 \mathrm{Lm}^{-2} \mathrm{~h}^{-1} \mathrm{bar}^{-1}$ and $98 \%$ respectively while for FSFO membrane the PWP and rejection were $1.012 \mathrm{Lm}^{-2} \mathrm{~h}^{-1} \mathrm{bar}^{-1}$ and 90\% respectively. In comparison to FSFO, HFFO membrane showed PWP value higher by $78 \%$ and salt rejection higher by $9 \%$.

Fig. 2 shows SEM images of both PA HFFO membrane and CTA FSFO membrane. Both membranes show a huge difference in making and structure. Fig 2 (a) shows top image of horizontally cut HFFO membrane. A thick PA active layer was seen on top of an outer layer of polyether sulphone. The PA active layer presents excellent intrinsic separation properties with a hydrophilic rejection layer that provide good mechanical strength to FO hollow fibers.

Similarly, in Fig. 2 (b), a side view of the CTA FS membrane shows top dense CTA layer embedded on a polyester mesh support layer. Membrane acetate contents (in wt.\%) directly affect the pure water permeability and salt permeability as well [40]. Water diffusion coefficient decreases as the acetate content of the membrane is increased. Similarly salt permeability is also reduced with any increase of membrane acetate contents suggests that a better CTA membrane may be made by controlling its acetate contents in the membrane along with the thickness of the membrane. 
Table 2. Comparison of FSFO and HFFO membrane characteristics and physical properties

\begin{tabular}{|c|c|c|}
\hline & Flat Sheet FO & Hollow Fiber FO \\
\hline Source & HTI, USA & $\begin{array}{l}\text { Samsung Cheil } \\
\text { Industries, Korea }\end{array}$ \\
\hline Active layer (AL) material & Cellulose Triacetate & Polyamide \\
\hline Support Layer (SL) material & Polyester mesh & Polyether sulphone \\
\hline Thickness (Overall) $(\mu \mathrm{m})$ & $91 \pm 2$ & $152 \pm 3$ \\
\hline Thickness (AL) $(\mu \mathrm{m})$ & $45 \pm 2$ & $65 \pm 3$ \\
\hline Thickness (SL) $(\mu \mathrm{m})$ & $46 \pm 2$ & $87 \pm 3$ \\
\hline Pure water permeability $\left(\mathrm{Lm}^{-2} \mathrm{~h}^{-1}\right.$ bar $\left.^{-1}\right)$ & 1.012 & 1.80 \\
\hline Salt rejection $(\%)$ & 90 & 98 \\
\hline Membrane surface charge & Negatively charge $^{a}$ & Neutrally charge $^{b}$ \\
\hline Support layer surface charge & Negatively charge & Neutrally charge \\
\hline Contact angle of the active layer $\left({ }^{\circ}\right)$ & $61^{c}$ & - \\
\hline Contact angle of the support layer $\left({ }^{\circ}\right)$ & $87^{d}$ & - \\
\hline
\end{tabular}

\section{2. Comparative performances of FO membranes in terms of water flux and reverse} solute flux

Lab FO units for both flat sheet membrane cell and hollow fiber module were operated on similar operation conditions. The FO flux outcome was evaluated for various fertilizer DS used in FDFO process and these results were then compared for their effectiveness for FDFO process. These were evaluations in term of AL-FS membrane orientations. Due to severe ICP issues, FO operation in this orientation relatively shows less flux output [44]. 

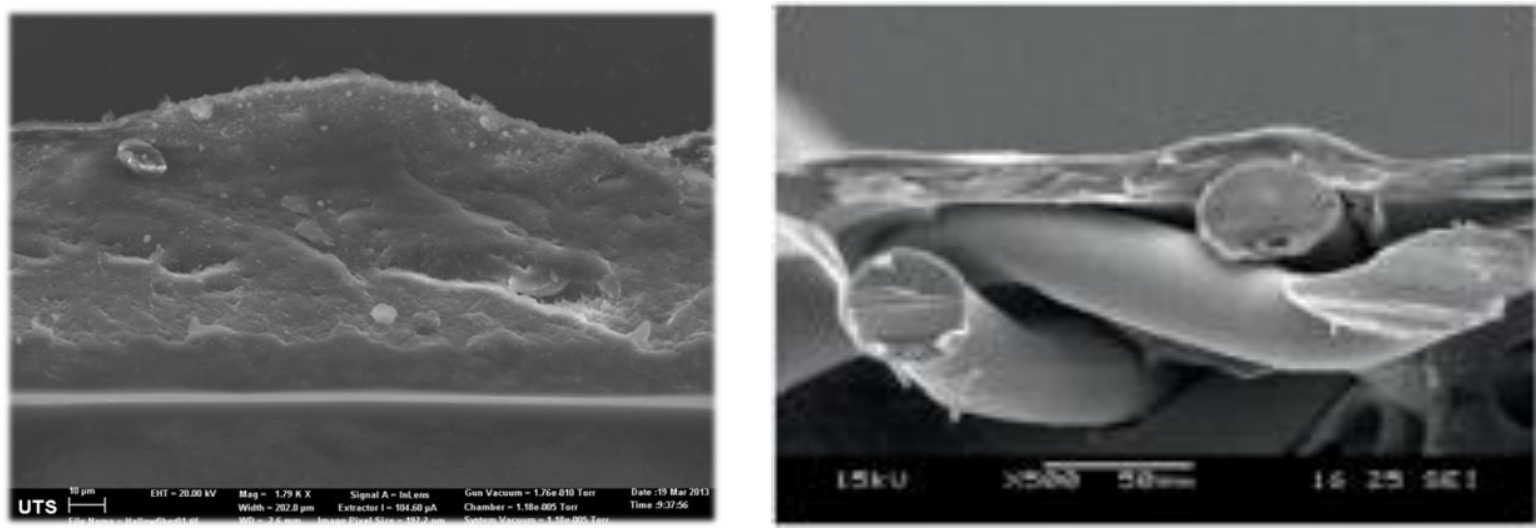

(d)
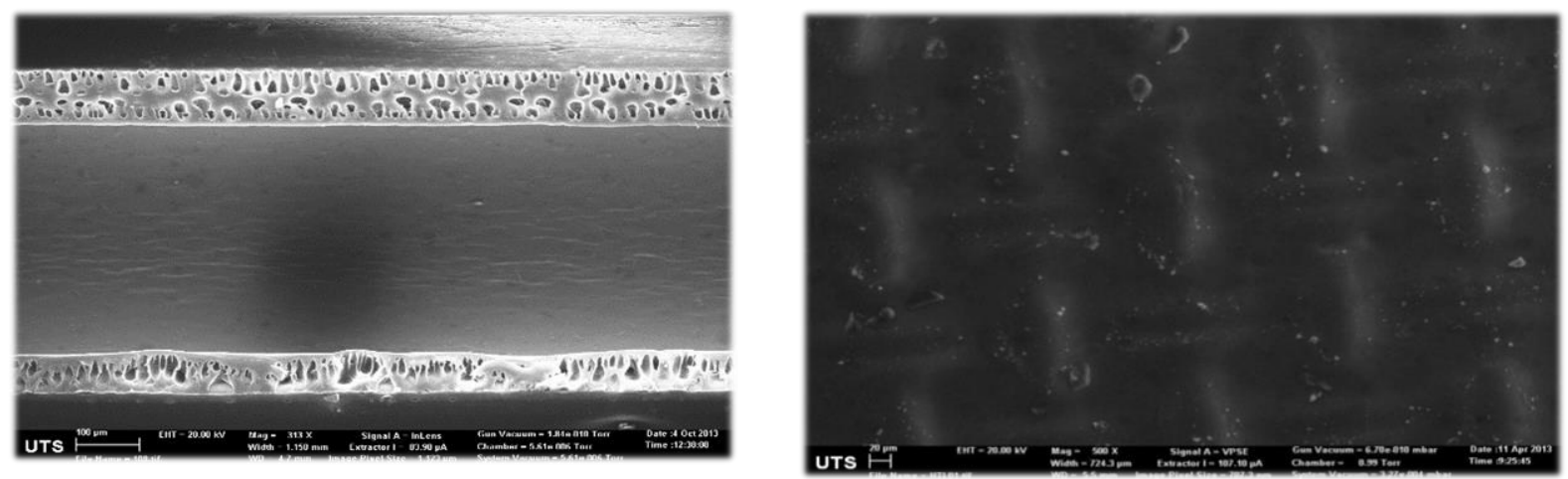

(f)
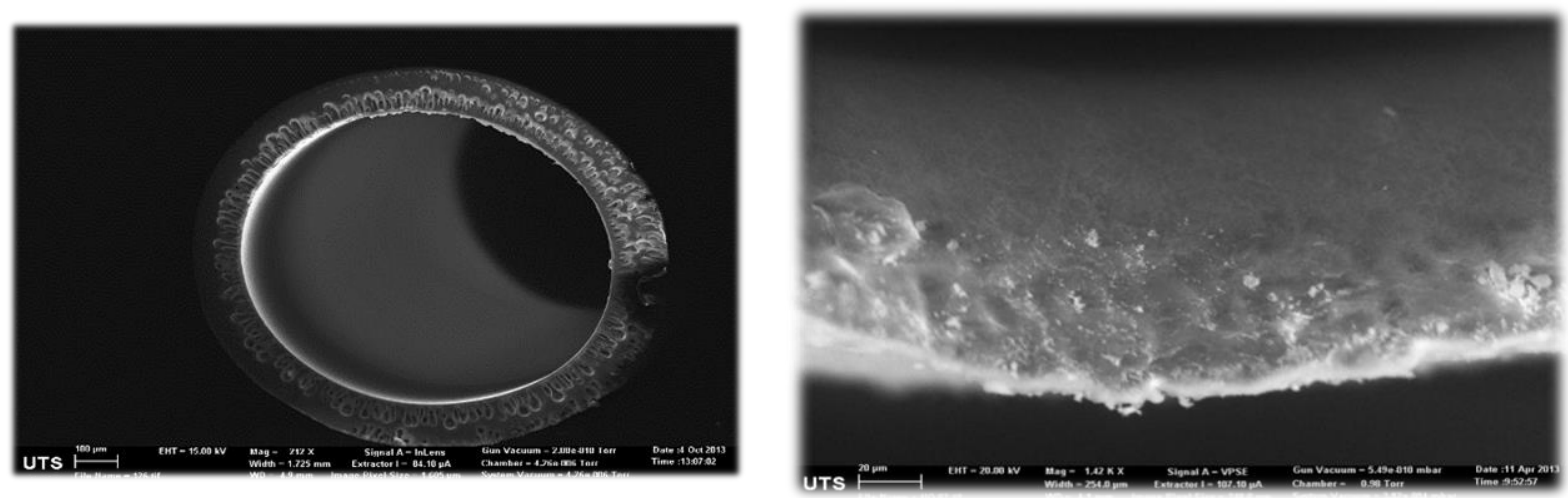

Fig 2. SEM images for both FO membranes used in our study. a) cross-section of HF FO membrane showing the inside active PA layer supported by outside PES layer b) FSFO membrane, with CTA active dense layer embedded on polyester mesh c) HFFO horizontally cut, larger view, d) FSFO active layer (top view) e \& f) HFFO cross-section. * adapted from [45] 


\subsection{Overall flux evaluation and comparison}

Fig. 3 shows the flux performances for HFFO (PA) membrane and compares it with FSFO (CTA) membrane flux results. These two membranes showed a mixed trend when HFFO flux output was compared with FSFO flux results using 9 different fertilizers including $\mathrm{NH}_{4} \mathrm{Cl}$, $\mathrm{Ca}\left(\mathrm{NO}_{3}\right)_{2}, \mathrm{NaNO}_{3}, \mathrm{KNO}_{3}, \mathrm{MAP},\left(\mathrm{NH}_{4}\right)_{2} \mathrm{SO}_{4}, \mathrm{KCl}, \mathrm{DAP}$ and urea as DS at $1 \mathrm{M}$ concentration. Some of the fertilizers DS showed comparatively higher flux outcome with HFFO membrane while others show lower flux. Results show that with these two FO membranes, flux varied from $-4 \%$ to $68 \%$ for different fertilizer DS. Urea showed the highest increase followed by $\mathrm{NaNO}_{3}, \mathrm{KNO}_{3}, \mathrm{MAP}$ and $\left(\mathrm{NH}_{4}\right)_{2} \mathrm{SO}_{4} . \mathrm{NH}_{4} \mathrm{Cl}, \mathrm{KCl}$ and $\mathrm{Ca}\left(\mathrm{NO}_{3}\right)_{2}$ showed lower flux results with HFFO membrane and DAP nearly gave the same flux. Urea, $\mathrm{NaNO}_{3}, \mathrm{MAP}, \mathrm{KNO}_{3}$ and $\left(\mathrm{NH}_{4}\right)_{2} \mathrm{SO}_{4}$ show that with HFFO, flux were increased by $67 \%, 32 \%, 25 \%$ and $8 \%$ respectively whereas $\mathrm{NH}_{4} \mathrm{Cl}, \mathrm{Ca}\left(\mathrm{NO}_{3}\right)_{2}$ and $\mathrm{KCl}$ respectively showed flux decrease of 4.0, 3.0 and $2.0 \%$ for HFFO. Flux for $\left(\mathrm{NH}_{4}\right)_{2} \mathrm{HPO}_{4}(\mathrm{DAP})$ nearly remained the same for both membranes.

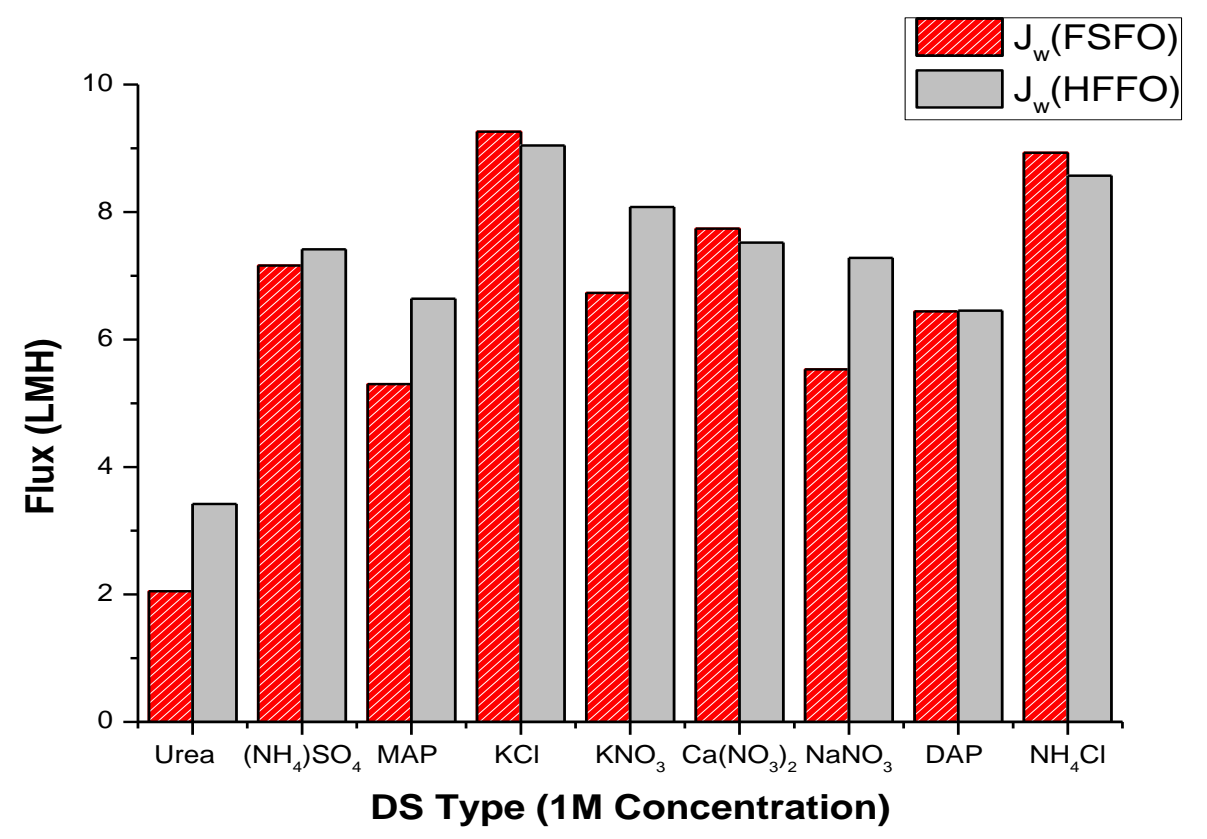

Fig. 3. Comparison of flux outcome for FSFO and HFFO membranes 
Comparing the physical appearance of the active layer of these two membranes (Fig. 2 (a and d)), it is evident that hollow fiber PA seems to be very porous as compared to a true dense flat sheet CTA membrane. Porous structure of HFFO membrane apparently helped diffuse water molecules comparatively easily and faster through the PA membrane surface and thus it

comparatively delivered high flux output. From the general theory of permeation and osmosis, it may be concluded that as HFFO substrates seem highly porous with a narrow pore size distribution against a really dense CTA layer of FSFO membrane, the latter might resist speedy penetration of water molecules deep through the membrane active layer at a high rate and thus deliver comparatively low flux.

Further, Fig. 3 results indicate that for these membranes, the flux variation with a particular DS is affected with the anion part of the DS solute. It was observed that most of nitrate based DS as $\mathrm{NaNO}_{3}$ and $\mathrm{KNO}_{3}$ gave higher flux with $\mathrm{HFFO}$ membrane and chloride based $\mathrm{DS}\left(\mathrm{NH}_{4} \mathrm{Cl}\right.$ and $\mathrm{KCl}$ ) provided higher flux with FSFO membranes. It is likely that smaller hydrated diameter species have more chances to diffuse through the membrane $[46,47]$. As the $\mathrm{NO}_{3}{ }^{-}$and $\mathrm{Cl}^{-}$anions carried the smallest hydrated radii size among all anions, they penetrated deep into the support layers of HFFO and FSFO membranes SL to reach close to the their active layers. However, active layers of these membranes responded differently for DS carrying $\mathrm{NO}_{3}{ }^{-}$and $\mathrm{Cl}^{-}$ and delivered inconsistent flux outcome. HFFO and FSFO membrane showed varying flux outcome for $\mathrm{NO}_{3}{ }^{-}$and $\mathrm{Cl}^{-}$based DS.

Moreover, the associated cationic part of the DS also significantly affects FO flux for a particular DS. HFFO membrane gave high flux with mono-valent cation based nitrate DS as $\mathrm{NaNO}_{3}$ and $\mathrm{KNO}_{3}$ whereas FSFO showed high flux with di-valent cation based nitrate DS as $\mathrm{Na}\left(\mathrm{NO}_{3}\right)_{2}$. This indicates that the FO flux for a particular membrane is associated with both DS properties and membrane characteristics.

Dense CTA flat sheet membranes gave lower water flux output due to increased CP phenomenon [28]. Interfacially polymerized TFC membranes on hydrophilic porous substrates shows reduced ICP effects and exhibits high water flux [48]. Hydrophilicity of porous substrates plays an important role on TFC FO membranes. These fluctuations in FO 
performance consequences for similar DS and operating conditions are attributed to the active rejection layer and support layer characteristics.

\subsection{Reverse solute flux (RSF) evaluation and comparison}

RSF of 8 fertilizers DS was evaluated for both HFFO and FSFO membranes. RSF is an important performance parameter used to evaluate the effectiveness of FO process as it represents the unwanted loss of valuable DS diffused through the FO membrane towards the feed solution, valuable fertilizer in the FDFO process. Difference of solute concentration in DS and FS on both side of the membrane drives RSF.

Overall, RSF results indicate that in comparison to FSFO membrane, HFFO performed extremely well for RSF outcome for most of the fertilizer DS. Contrary to flux outcome comparison, irregular behavior was observed when HFFO and FSFO membranes RSF results were evaluated and compared for different fertilizer DS (1M concentrations). Most of the fertilizer DS showed very low RSF with $\mathrm{HFFO}$ (Fig. 4). $\mathrm{NH}_{4} \mathrm{H}_{2} \mathrm{PO}_{4}, \mathrm{KCl}, \mathrm{KNO}_{3}, \mathrm{KCl}, \mathrm{NH}_{4} \mathrm{Cl}$ and MAP DS gave lower RSF values whereas $\left(\mathrm{NH}_{4}\right)_{2} \mathrm{SO}_{4}$ and $\mathrm{Ca}\left(\mathrm{NO}_{3}\right)_{2}$ comparatively delivered higher RSF values among these fertilizers.

The results in Fig. 4 were evaluated for RSF percentage variation for HFFO and FSFO membranes. FSFO membrane showed relatively inferior results for RSF. Comparison to HFFO, FSFO membrane showed 1145\%,739\%, 650\%, 727\%, 280\% and 1058\% higher RSF for $\mathrm{NH}_{4} \mathrm{H}_{2} \mathrm{PO}_{4}, \mathrm{KCl}, \mathrm{KNO}_{3}, \mathrm{NaNO}_{3}, \mathrm{DAP}$ and $\mathrm{NH}_{4} \mathrm{Cl}$ DS respectively.

Further, $\mathrm{NH}_{4} \mathrm{Cl}$ and $\mathrm{KCl}$ DS carrying monovalent cations and anion gave similar RSF for FSFO and HFFO membrane whereas the other DS pair as $\mathrm{KNO}_{3}$ and $\mathrm{NaNO}_{3}$ also carrying monovalent cations and anions showed significant difference in RSF outcome (Fig. 4). $\mathrm{Ca}\left(\mathrm{NO}_{3}\right)_{2}$ and $\left(\mathrm{NH}_{4}\right)_{2} \mathrm{SO}_{4}$ carrying a divalent cation and divalent anion showed less RSF with both membranes. $\mathrm{Ca}^{2+}$ thus shows less $\mathrm{RSF}$ as compared to $\mathrm{Na}^{+}$or $\mathrm{K}^{+}$. HFFO membrane comparatively indicated the high RSF value for divalent cation and anion based DS such as $\left(\mathrm{NH}_{4}\right)_{2} \mathrm{SO}_{4}$ and $\mathrm{Ca}\left(\mathrm{NO}_{3}\right)_{2}$. Divalent cations and anions $\left(\mathrm{Ca}^{2+}, \mathrm{SO}_{4}{ }^{2-}\right)$ or trivalent anions $\left(\mathrm{PO}_{4}{ }^{3-}\right)$ have high hydrated radii, hence exhibits low RSF.

FSFO showed better performance in terms of $\mathrm{RSF}$ for $\left(\mathrm{NH}_{4}\right)_{2} \mathrm{SO}_{4}$ and $\mathrm{Ca}\left(\mathrm{NO}_{3}\right)_{2}$ DS as it respectively showed $82 \%$ and $36 \%$ less RSF for these two DS. Low RSF demonstrated by FSFO 
membrane for divalent ionic compounds could be attributed to ion size exclusion and Donnan electrostatic effect FSFO $[17,25]$. Comparative data also proved that divalent cations or anions reduce or slow down the relative permeation of respective mono-valent cations and anions.

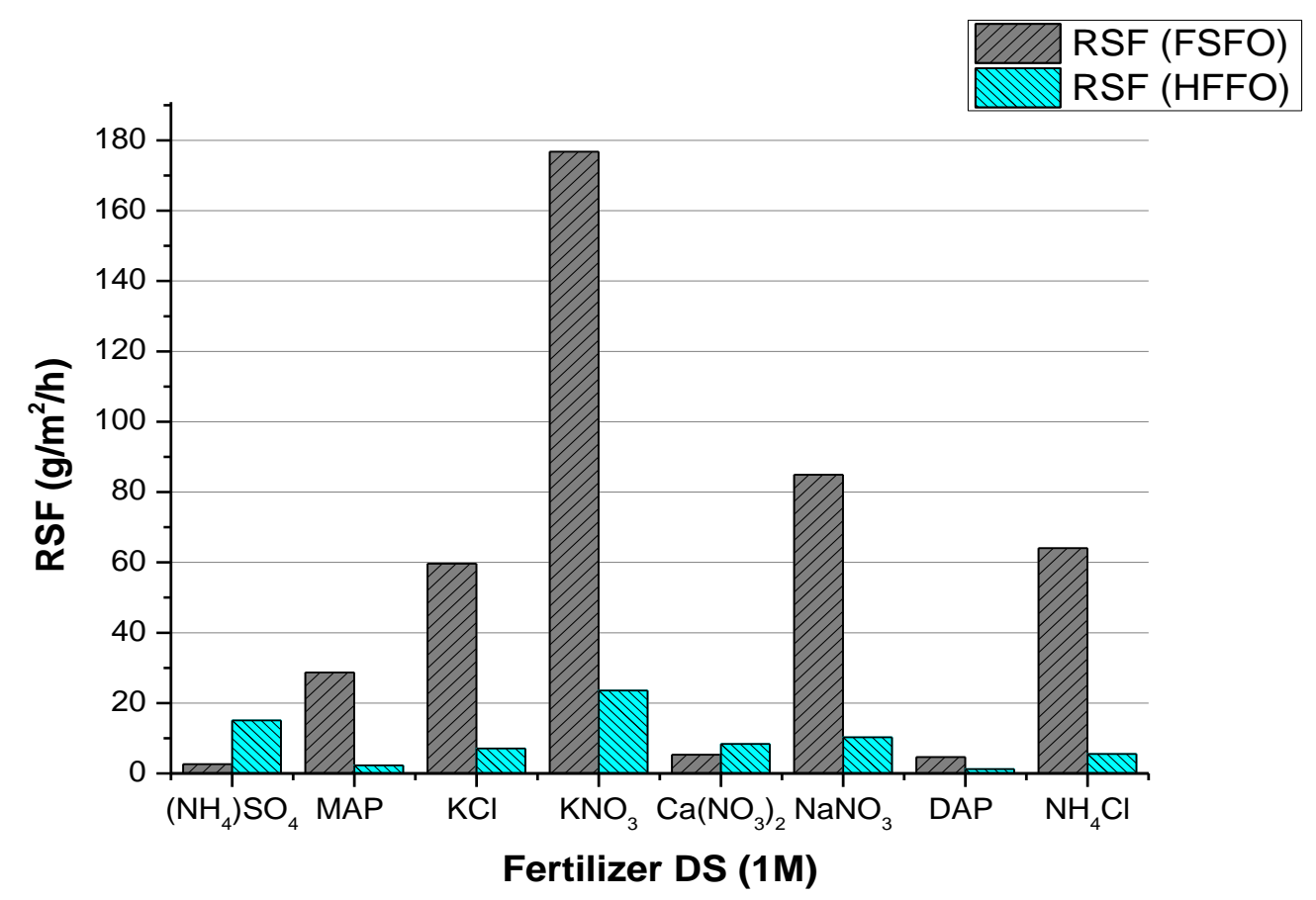

Fig. 4. RSF with HFFO and FSFO membranes for fertilizer DS

\subsection{Flux and RSF behavior with hydrated radii}

For water permeation (flux) or a salt diffusion (RSF) through a specific membrane, both size of water molecule and DS species matter are important. DS ionic size, solute structure and membrane pore shape play an important role in delivering any particular flux through the membrane. FO performance related parameters as flux and RSF have affinity between DS radii, water molecule size and membrane pore size. Ionic and dipole permeabilities are extremely sensitive to the ionic/dipolar radii $[49,50]$. Large molecules are retained at the membrane surface by electrostatic interactions whereas small, weakly charged ions can enter the pores. Anions hold their hydration shells relatively more strongly than the cations for a given charge density [51]. 
Fig. 3 shows that HFFO membrane exhibited better flux outcome for a particular DS carrying the same osmotic pressure. For many reasons, solute concentration alone is not sufficient to give good estimates of osmotic pressure [52]. Osmotic pressure is not solely a function of the number of solute particles in solution, but it is also related to the solute size [53]. Osmotic potential of organic solutions is largely a function of the size of their solute particles [54]. Solutes influence osmotic potential by altering the molecular spacing of the free water molecules in solution and therefore different solutes differently influence the osmotic potential [55]. This also authenticates that a close relation between the hydrated radii and membrane pore size.

Results presented in Fig. 3 and 4 are further evaluated with different prevailing theories to further identify the main issues related to the difference in performance of these two membranes.

Both HFFO and FSFO membranes were asymmetric and permeable to both salt and water. Water flux and salt diffusion seem to be closely linked with each other. Results from Fig. 4 indicate the influence of interactions of some strange intermolecular and intramolecular forces which play an important role for the specific diffusion of different solutes through semipermeable membranes. Characterizing DS by their valancy, comparison of the results in Fig. 4 shows that DS containing monovalent cations $\left(\mathrm{NH}_{4}{ }^{+}, \mathrm{K}^{+}\right)$and anions $\left(\mathrm{NO}_{3}{ }^{-}, \mathrm{Cl}^{-}\right)$exhibited better results with HFFO CA membrane. DS containing either a divalent cation $\left(\mathrm{Ca}^{2+}\right)$ or divalent anion $\left(\mathrm{SO}_{4}{ }^{2-}\right)$ exhibited better performance for RSF with CTA flat sheet FO membrane. Low RSF for divalent cation and anion based DS showed that CTA FSFO membrane behaves similar to NF membrane for divalent ions rejection properties. Inconsistent trends for RSF results may only be associated with the membrane active layer properties as their surface charge, membrane pore size and pore geometry.

Fig. 4 indicates that RSF for monovalent cation based $\mathrm{NO}_{3}{ }^{-}$and $\mathrm{Cl}^{-} \mathrm{DS}$ reduced significantly with HFFO membrane. AL of HF membrane does not allow nitrates to diffuse through the PA active layer. In comparison to HFFO, FSFO membrane showed $650 \%$ and $727 \%$ higher RSF for $\mathrm{KNO}_{3}$ and $\mathrm{NaNO}_{3}$ respectively. Nitrate based DS exhibited high flux and lower RSF with HFFO (Fig 3 and 4). Furthermore, compared to FSFO, HFFO membrane showed $739 \%$ and $1054 \%$ lower RSF for chloride based DS. However, chloride based DS showed higher flux for FSFO membrane. 
The results indicate that in comparison to CTA FSFO, PA HFFO membrane carry smaller pore with unique configurations which reduce RSF through the membrane. These membrane pores do not allow even the smaller size $\mathrm{Cl}^{-}$and $\mathrm{NO}_{3}{ }^{-}$ions pass through the HF membrane but at the same time high RSF value for divalent DS indicates that the membrane allows DS carrying large size divalent $\mathrm{Ca}^{2+}$ and $\mathrm{SO}_{4}{ }^{2-}$ move faster through the membrane. It confirms that only hydrated radii size does not direct flux or RSF for any membrane rather membrane properties are more vital for FO performance. Similarly the pore size of membrane AL may not suggest any particular flux or RSF outcome. PA membrane showed better control of monovalent cationic or anionic DS whereas CTA membrane shows better control of diffusion for divalent cation or anion based DS.

In any FO process, RSF and water flux movement through the FO membrane is in opposite directions [56, 57]. Water molecules in a high flux FO process push solute molecules backward and result low RSF. Similar types of opposite forces affect osmosis and diffusion for all flux and RSF outcome. Fig. 3 and 4 show that high FO flux outcome reduces RSF. RSF does not reduce linearly with the flux rise for all evaluated DS which indicates that flux rise itself does affect RSF outcome significantly. Literature still lacks data which may exactly define water and solutes molecules movement patterns through the membrane pores during any membrane filtration process as NF, RO, and FO. Due to these unclear hidden issues, effects of such phenomenon are not yet incorporated to derive equations for FO flux and RSF.

It is impossible to have an ideal membrane of zero thickness [58]. All natural and synthetic membranes come with a finite thickness. Table 2 shows that HFFO membrane comparatively carry thick active layer and support layer. HFFO membrane exhibited same thickness same as of conventional RO membrane [59]. Water molecules face more obstacles to cross thicker membrane. Higher flux with HFFO membrane indicated that thin active layer of FSFO has dense and non-porous membrane structure. Due to smooth pore geometry and structure, water molecules comparatively have better probability to move quickly through micro porous HFFO membrane structure shown in Fig. 2 (a).

Fouling development reduces water flux sharply as fouling make water diffusion passage through the membrnae thick [44]. Fouling tends to increase the thickness of the membrane which hamper flow of water molecules but flux reduction due to fouling and scaling is mianly 
contributed due to pore blocking [60]. Membrane development work is focused to construct a thinner membrane, however, Fig. 3 results indicate that only the thickness of the specific membrane does not effect FO flux notably rather it highlighted role of other membrane chracteristics as pore density, pore size, pore structure and pore depth which are not yet evlauted in details. These parameters seem more cricitial and relevant than membrane thickness for FO flux and RSF outcome. However, influence of AL thickness on FO outcome is not ruled out completely.

$\mathrm{CP}$ reduces the net osmotic pressure available across the AL of FO membrane [3]. In FO process, $\mathrm{CP}$ increases as the thickness of the membrane or SL increases [3, 16, 61-63]. ICP effects can be reduce by using thinner and more porous support layer as it reduces mass transfer resistance [14]. For most of the DS, higher flux outcome (Fig. 3) by HFFO membrane comprises of thick active and support layers (Table 2) reveal that the thickness of the membrane may not be considered as the main parameter linked to $\mathrm{CP}$ rather AL and SL membrane material characteristics and DS properties together contribute to CP build-up in diverse ways.

Fig. 3 and 4 results indicate that for different DS, both HFFO and FSFO membranes showed varying behaviors for flux and RSF outcome. It is evident from these results that the differences in flux and RSF outcome are owing to varying membrane properties and DS characteristics as well. Different DS affects flux and RSF performance inconsistently for these membranes as for $1 \mathrm{M} \mathrm{KNO}_{3} \mathrm{DS}$, water flux increases whereas RSF decreases for HFFO membrane. Similar types of varying results were also noticed with other evaluated DS. DS properties seem directly linked with membrane structure, porosity, pore density, pore size, pore structure, solute affinity with water, AL and SL membrane surface charge, membrane thickness, water and solute flow patterns within membrane pores for any particular FO performance outcome. Further studies on these fundamental parameters are suggested to understand and predict any resultant FO flux or RSF outcome for a specific membrane.

\section{Conclusions}

PA HFFO and CTA FSFO membranes were evaluated in this study for FDFO process. Summarizing main findings of our study as:

- HFFO membrane comparatively gave up to $66 \%$ higher flux outcome for different fertilizer DS. 
- HFFO membrane performed well for RSF as FSFO showed up to $1184 \%$ higher RSF values for fertilizer DS. Most of the DS showed lower RSF values with HFFO except DS having divalent cations or anions.

- FO flux and RSF outcome for FO membranes are mainly associated with hydrated radii of anions associated with other cation of the DS. Most of the $\mathrm{Cl}^{-}$based DS gave better flux outcome with FSFO whereas $\mathrm{NO}_{3}{ }^{-}$based DS exhibited better flux results with HFFO. Divalent cationic or anionic parts of the DS significantly affected RSF and flux results.

- The study confirms close links and associations between DS properties and membrane characteristics for FO performance.

Higher water flux and low RSF outcome for HFFO membrane confirmed that HFFO membrane is a better choice for FDFO process.

\section{Acknowledgments}

The authors would like to thank National Centre for Excellence in Desalination, Australia (NCEDA) sponsored by Australian Government through Water for Future Initiative for their support to this study. We also acknowledge Samsung Cheil Industries, Korea and HTI, USA for providing membranes for this study.

\section{References}

[1] M. Mulder, Basic Principles of Membrane Technology Second Edition: Kluwer Academic Pub, 1996.

[2] R. Baker, Membrane technology and applications: Wiley, 2012.

[3] J.R. McCutcheon, R.L. McGinnis and M. Elimelech, A novel ammonia — carbon dioxide forward (direct) osmosis desalination process, Desalination, 174 (2005), 1-11.

[4] J.O. Kessler and C.D. Moody, Drinking water from sea water by forward osmosis, Desalination, 18 (1976), 297-306.

[5] R.L. McGinnis, N.T. Hancock, M.S. Nowosielski-Slepowron and G.D. McGurgan, Pilot demonstration of the NH3/CO2 forward osmosis desalination process on high salinity brines, Desalination, 312 (2013), 67-74.

[6] E.M. Garcia-Castello, J.R. McCutcheon and M. Elimelech, Performance evaluation of sucrose concentration using forward osmosis, J. Membrane Sci., 338 (2009), 61-66.

[7] S. Phuntsho, H.K. Shon, S. Hong, S. Lee and S. Vigneswaran, A novel low energy fertilizer driven forward osmosis desalination for direct fertigation: Evaluating the performance of fertilizer draw solutions, J. Membrane Sci., 375 (2011), 172-181.

[8] J.R. McCutcheon, R.L. McGinnis and M. Elimelech, Desalination by ammonia-carbon dioxide forward osmosis: Influence of draw and feed solution concentrations on process performance, J. Membrane Sci., 278 (2006), 114-123.

[9] T.Y. Cath, A.E. Childress and M. Elimelech, Forward osmosis: Principles, applications, and recent developments, J. Membrane Sci., 281 (2006), 70-87.

[10] J.R. McCutcheon and M. Elimelech, Influence of membrane support layer hydrophobicity on water flux in osmotically driven membrane processes, J. Membrane Sci., 318 (2008), 458-466. 
[11] W. Lay, T.H. Chong, C.Y. Tang, A.G. Fane, J. Zhang and Y. Liu, Fouling propensity of forward osmosis: investigation of the slower flux decline phenomenon, Water Sci. Technol., 61 (2010), p.927.

[12] S. Zhang, K.Y. Wang, T.-S. Chung, H. Chen, Y. Jean and G. Amy, Well-constructed cellulose acetate membranes for forward osmosis: minimized internal concentration polarization with an ultra-thin selective layer, J. Membrane Sci., 360 (2010), 522-535.

[13] J.R. McCutcheon and M. Elimelech, Influence of concentrative and dilutive internal concentration polarization on flux behavior in forward osmosis, J. Membrane Sci., 284 (2006), 237-247.

[14] W. Li, Y. Gao and C.Y. Tang, Network modeling for studying the effect of support structure on internal concentration polarization during forward osmosis: Model development and theoretical analysis with FEM, J. Membrane Sci., 379 (2011), 307-321.

[15] E. Cornelissen, D. Harmsen, K. De Korte, C. Ruiken, J.-J. Qin, H. Oo and L. Wessels, Membrane fouling and process performance of forward osmosis membranes on activated sludge, J. Membrane Sci., 319 (2008), 158-168.

[16] C.Y. Tang, Q. She, W.C.L. Lay, R. Wang and A.G. Fane, Coupled effects of internal concentration polarization and fouling on flux behavior of forward osmosis membranes during humic acid filtration, $\mathrm{J}$. Membrane Sci., 354 (2010), 123-133.

[17] Q. Yang, K.Y. Wang and T.-S. Chung, Dual-Layer Hollow Fibers with Enhanced Flux As Novel Forward Osmosis Membranes for Water Production, Environ. Sci. Technol., 43 (2009), 2800-2805.

[18] S. Chou, R. Wang, L. Shi, Q. She, C. Tang and A.G. Fane, Thin-film composite hollow fiber membranes for pressure retarded osmosis (PRO) process with high power density, J. Membrane Sci., 389 (2012), 2533.

[19] R. Wang, L. Shi, C.Y. Tang, S. Chou, C. Qiu and A.G. Fane, Characterization of novel forward osmosis hollow fiber membranes, J. Membrane Sci., 355 (2010), 158-167.

[20] N.Y. Yip, A. Tiraferri, W.A. Phillip, J.D. Schiffman and M. Elimelech, High performance thin-film composite forward osmosis membrane, Environ. Sci. Technol., 44 (2010), 3812-3818.

[21] M. Amini, M. Jahanshahi and A. Rahimpour, Synthesis of novel thin film nanocomposite (TFN) forward osmosis membranes using functionalized multi-walled carbon nanotubes, J. Membrane Sci., 435 (2013), 233-241.

[22] C.Y. Tang, Q. She, W.C. Lay, R. Wang, R. Field and A.G. Fane, Modeling double-skinned FO membranes, Desalination, 283 (2011), 178-186.

[23] I.-C. Kim, S.-H. Ahn, Y.-S. Jin, B.-S. Kim, Y.-I. Park, J. Jegal, S.-H. Lee, Y.-N. Kwon and H.-W. Rhee, Preparation of newly synthesized forward osmosis membrane, Desal. Wat. Treat., 51 (2013), 5191-5195.

[24] T.P.N. Nguyen, E.-T. Yun, I.-C. Kim and Y.-N. Kwon, Preparation of cellulose triacetate/cellulose acetate (CTA/CA)-based membranes for forward osmosis, J. Membrane Sci., 433 (2013), 49-59.

[25] K.Y. Wang, T.-S. Chung and J.-J. Qin, Polybenzimidazole (PBI) nanofiltration hollow fiber membranes applied in forward osmosis process, J. Membrane Sci., 300 (2007), 6-12.

[26] K.Y. Wang, Q. Yang, T.-S. Chung and R. Rajagopalan, Enhanced forward osmosis from chemically modified polybenzimidazole (PBI) nanofiltration hollow fiber membranes with a thin wall, Chem. Eng. Sci., 64 (2009), 1577-1584.

[27] S. Chou, L. Shi, R. Wang, C.Y. Tang, C. Qiu and A.G. Fane, Characteristics and potential applications of a novel forward osmosis hollow fiber membrane, Desalination, 261 (2010), 365-372.

[28] J. Su, Q. Yang, J.F. Teo and T.-S. Chung, Cellulose acetate nanofiltration hollow fiber membranes for forward osmosis processes, J. Membrane Sci., 355 (2010), 36-44.

[29] E. Sivertsen, T. Holt, W. Thelin and G. Brekke, Modelling mass transport in hollow fibre membranes used for pressure retarded osmosis, J. Membrane Sci., 417-418 (2012), 69-79.

[30] D. Xiao, W. Li, S. Chou, R. Wang and C.Y. Tang, A modeling investigation on optimizing the design of forward osmosis hollow fiber modules, J. Membrane Sci., 392-393 (2012), 76-87.

[31] L. Setiawan, R. Wang, K. Li and A.G. Fane, Fabrication of novel poly (amide-imide) forward osmosis hollow fiber membranes with a positively charged nanofiltration-like selective layer, J. Membrane Sci., 369 (2011), 196-205.

[32] W. Fang, R. Wang, S. Chou, L. Setiawan and A.G. Fane, Composite forward osmosis hollow fiber membranes: Integration of RO-and NF-like selective layers to enhance membrane properties of antiscaling and anti-internal concentration polarization, J. Membrane Sci., 394 (2012), 140-150.

[33] M. Elimelech, Yale constructs forward osmosis desalination pilot plant, Membrane tech., 2007 (2007), 7-8.

[34] C.R. Martinetti, A.E. Childress and T.Y. Cath, High recovery of concentrated RO brines using forward osmosis and membrane distillation, J. Membrane Sci., 331 (2009), 31-39.

[35] Hydration Technology Innovations, LLC. Available: http://www.htiwater.com/divisions/oilgas/index.html, March 05, 2013. 
[37] Modern Water Plc. Available: http://www.modernwater.com/membrane-processes/membranedesalination, February 19, 2013.

[38] Statkraft AS. Available: http://www.statkraft.com/energy-sources/osmotic-power/prototype/, January 14, 2013.

[39] NASA. Available: http://www.nasa.gov/mission pages/station/research/experiments/846.html, March 04, 2013.

[40] H.K. Lonsdale, U. Merten and R.L. Riley, Transport properties of cellulose acetate osmotic membranes, J. Appl. Polym. Sci., 9 (1965), 1341-1362.

[41] A. Tiraferri and M. Elimelech, Direct quantification of negatively charged functional groups on membrane surfaces, J. Membrane Sci., 389 (2012), 499-508.

[42] M. Xie, W.E. Price, L.D. Nghiem and M. Elimelech, Effects of feed and draw solution temperature and transmembrane temperature difference on the rejection of trace organic contaminants by forward osmosis, J. Membrane Sci., 438 (2013), 57-64.

[43] A. Achilli, T. Cath and A. Childress, Selection of inorganic based draw solutions for forward osmosis applications, J. Membrane Sci., 364 (2010), 233-241.

[44] Y. Wang, F. Wicaksana, C.Y. Tang and A.G. Fane, Direct Microscopic Observation of Forward Osmosis Membrane Fouling, Environ. Sci. Technol., 44 2010/09/15 (2010), 7102-7109.

[45] T.-S. Chung, X. Li, R.C. Ong, Q. Ge, H. Wang and G. Han, Emerging forward osmosis (FO) technologies and challenges ahead for clean water and clean energy applications, Curr. Opin. Chem. Eng., 1 (2012), 246-257.

[46] L. Paugam, S. Taha, G. Dorange, P. Jaouen and F. Quéméneur, Mechanism of nitrate ions transfer in nanofiltration depending on pressure, $\mathrm{pH}$, concentration and medium composition, J. Membrane Sci., 231 (2004), 37-46.

[47] J. Kielland, Individual activity coefficients of ions in aqueous solutions, J. Am. Chem. Soc., 59 (1937), 1675-1678.

[48] E. Sivertsen, T. Holt, W. Thelin and G. Brekke, Pressure retarded osmosis efficiency for different hollow fibre membrane module flow configurations, Desalination, 312 (2013), 107-123.

[49] A. Volkov, S. Paula and D. Deamer, Two mechanisms of permeation of small neutral molecules and hydrated ions across phospholipid bilayers, Bioelectroch. Bioener., 42 (1997), 153-160.

[50] B.E. Conway and B. Conway, Ionic hydration in chemistry and biophysics vol. 741: Elsevier Amsterdam, 1981.

[51] B. Tansel, J. Sager, T. Rector, J. Garland, R.F. Strayer, L. Levine, M. Roberts, M. Hummerick and J. Bauer, Significance of hydrated radius and hydration shells on ionic permeability during nanofiltration in dead end and cross flow modes, Sep. Purif. Technol., 51 (2006), 40-47.

[52] R.R.A. Robinson and R.R.H. Stokes, Electrolyte solutions: Courier Dover Publications, 1970.

[53] A. Grattoni, M. Merlo and M. Ferrari, Osmotic Pressure beyond Concentration Restrictions, J. Phys. Chem. B, 111 (2007), 11770-11775.

[54] T.T. Cochrane and T.A. Cochrane, Osmotic Properties of Organic and Inorganic Solutes and Their Influence on Flow At Different Stages of the Soil-Plant Solution Continuum, Soil Sci., 172 (2007), 386395.

[55] V.T. Granik, B.R. Smith, S.C. Lee and M. Ferrari, Osmotic Pressures for Binary Solutions of Nonelectrolytes, Biomed. Microdevices, 4 (2002), 309-321.

[56] M. Elimelech and S. Bhattacharjee, A novel approach for modeling concentration polarization in crossflow membrane filtration based on the equivalence of osmotic pressure model and filtration theory, J. Membrane Sci., 145 (1998), 223-241.

[57] J. Su, T.-S. Chung, B.J. Helmer and J.S. de Wit, Understanding of low osmotic efficiency in forward osmosis: Experiments and modeling, Desalination, 313 (2013), 156-165.

[58] M.P. Tombs and A.R. Peacocke, The osmotic pressure of biological macromolecules: Clarendon Press Oxford, 1974.

[59] J. Wei, C. Qiu, C.Y. Tang, R. Wang and A.G. Fane, Synthesis and characterization of flat-sheet thin film composite forward osmosis membranes, J. Membrane Sci., 372 (2011), 292-302.

[60] E. Arkhangelsky, F. Wicaksana, S. Chou, A.A. Al-Rabiah, S.M. Al-Zahrani and R. Wang, Effects of scaling and cleaning on the performance of forward osmosis hollow fiber membranes, J. Membrane Sci., 415-416 (2012), 101-108.

[61] S. Loeb, L. Titelman, E. Korngold and J. Freiman, Effect of porous support fabric on osmosis through a Loeb-Sourirajan type asymmetric membrane, J. Membrane Sci., 129 (1997), 243-249.

[62] R.L. McGinnis and M. Elimelech, Energy requirements of ammonia-carbon dioxide forward osmosis desalination, Desalination, 207 (2007), 370-382. 
[63] A. Achilli, T.Y. Cath and A.E. Childress, Power generation with pressure retarded osmosis: An experimental and theoretical investigation, J. Membrane Sci., 343 (2009), 42-52. 